\title{
OS NOMES E AS LÍNGUAS DE ARYON
}

\section{THE NAMES AND THE LANGUAGES OF ARYON}

\author{
Taís da Silva Martins \\ Universidade Federal de Santa Maria, UFSM, Santa Maria, RS, Brasil \\ Liana Cristina Giachini \\ Universidade Federal de Santa Maria, UFSM, Santa Maria, RS, Brasil
}

\begin{abstract}
Resumo: Este texto tem como objetivo trazer à tona o discurso sobre o importante linguista brasileiro Aryon Dall'Igna Rodrigues, posterior ao seu falecimento. Cabe ressaltar que analisamos, também, as condiçôes de produção sócio-históricas que são constitutivas do discurso sobre esse pesquisador, entendendo-as como determinantes do dizer. Para tanto, constituímos um arquivo composto por textos veiculados na mídia eletrônica, a partir dos quais recortamos materialidades discursivas em que identificamos regularidades e descontinuidades em relação ao processo de designação. Nosso escopo teórico estabelece uma articulação entre a História das Ideias Linguísticas e a Análise de Discurso peucheutiana.
\end{abstract}

Palavras-chave: Discurso; Arquivo; Linguística.

Abstract: This paper aims to bring out the discourse on the important Brazilian linguist Aryon Dall'Igna Rodrigues subsequent to his death. We emphasize that we have also analyzed the socio-historical conditions of production that are constitutive of the discourse on this researcher, understanding them as determinants of saying. Therefore, we have established an archive consisting of texts posted on electronic media from which we collected discursive materialities where we identified regularities and discontinuities in relation to the designation process. Our theoretical scope establishes a link between the History of Linguistic Ideas and Pêcheux's Discourse Analysis.

Keywords: Discourse; Archive; Linguistics.

Não há, pois, como desconhecer a história do sujeito e da língua na produção do conhecimento do sujeito sobre a lingua".

(ORLANDI, 2002, p. 29)

\section{Introduçáo}

Este breve texto foi escrito com o intuito de compreender como a história da vida e da obra científica do pesquisador são representadas nas formas de designar Aryon Rodrigues, levando em conta as condiçôes de produção do discurso sobre o autor após o seu falecimento. 
Para nós, falar (escrever) sobre Aryon Dall'Igna Rodrigues não é uma tarefa nada fácil. Sabemos que, quaisquer homenagens que possamos fazer a esse grande linguista, elas jamais alcançarão a amplitude necessária para abarcar sua grande obra. Professor, autor, pesquisador, linguista, inúmeras são as designações que podem ser atribuídas a essa importante figura das Letras no Brasil, cujo interesse pelas línguas se manifestou de forma muito precoce. O jovem Aryon publicou seu primeiro texto sobre as línguas indígenas ainda aos dezessete anos, com o título " $O$ artigo definido e os numerais na língua Kiriri. Vocabulários Português Kiriri e Kiriri-Português”, nos Arquivos do Museu Paranaense. Aluno de Mansur Guérios (19071984), fundador do curso de Letras da Universidade Federal do Paraná (UFPR), o precoce estudioso encontrou no sábio professor o incentivo necessário para iniciar sua importante produção acadêmica. Nas palavras de D’Angelis (2014, p. 1) "indiscutivelmente, Aryon Rodrigues foi quem mais contribuiu, até hoje, para o conhecimento das relaçôes genéticas internas no tronco Tupi e na família Tupi-Guarani”, o que lhe garante ocupar o lugar institucional de linguista e indigenista.

Além disso, com o desaparecimento de Aryon Dall' Igna Rodrigues, a Ciência Linguística Brasileira perdeu um de seus maiores nomes. Falecido em abril de 2014, Rodrigues deixou o legado de uma grande obra como linguista e indigenista. E, neste texto, que possui entre seus objetivos investigar a importância atribuída aos estudos de Rodrigues no cenário da Linguística, estabelecemos uma articulação entre a História das Ideias Linguísticas e a Análise de Discurso, a fim de compreender como o lugar ocupado por esse pesquisador é representado metaforicamente em textos veiculados na mídia eletrônica em razão de seu falecimento. Para tanto, constituímos um arquivo composto por textos veiculados neste meio, a partir dos quais recortamos materialidades discursivas em que identificamos regularidades e descontinuidades em relação ao processo de designaçáo.

Destacamos que, ao buscarmos a compreensão do discurso produzido sobre o autor após o seu falecimento (por meio de textos publicados na mídia digital), nos deparamos com o fato de que há uma estreita relação entre a vida do pesquisador e a história da própria Linguística, que, por vezes, se fundem, conforme veremos na sequência. 


\title{
A Linguística no Brasil
}

Os primeiros cursos de Letras no Brasil surgiram, respectivamente, nos anos de 1934, 1935 e 1939, na Universidade de São Paulo (Faculdade de Filosofia, Ciências e Letras), na Universidade do Distrito Federal (Faculdade Nacional de Filosofia da Universidade do Brasil) e na Universidade de Minas Gerais.

Sobre o início da pesquisa linguística no país, Fiorin salienta que:

\begin{abstract}
A pesquisa Linguística na universidade brasileira surge com a criaçáo dos Cursos de Letras. Estes aparecem no Brasil no bojo dos projetos de criaçáa das Faculdades de Filosofia apenas nos anos 30 do século passado, embora houvesse reivindicaçōes anteriores para a existência de uma formação superior em línguas e literaturas e mesmo experiências efêmeras no início do século XX (FIORIN, 2006, p. 12).
\end{abstract}

É no ano de 1938 que, pela primeira vez, é instituído um curso extensivo de Linguística em um curso de Letras, o qual, naquele momento, fora ministrado por Joaquim Mattoso Câmara Junior, na Universidade do Distrito Federal, no Rio de Janeiro. Mattoso, entretanto, ministrou por apenas dois anos a disciplina de Linguística Geral, pelo fato de tal universidade, criada em 1935, ter sido extinta no ano de 1939.

De acordo com Rodrigues (2005), a Universidade do Distrito Federal era uma instituição inovadora e liberal e, portanto, por determinação de uma reação conservadora tomada diante da emergência do Estado Novo, ela foi extinta. Em seu lugar foi instaurada a Universidade do Brasil e criada a Faculdade Nacional de Filosofia, também situada no Rio de Janeiro.

Contudo, nos programas do Curso de Letras da Faculdade Nacional de Filosofia, náo figurava a disciplina de Linguística, o que, para o mesmo autor, se configurou em um decréscimo científico, uma vez que tal faculdade "instalou uma versão mais antiquada e menos científica do ensino na área de línguas e literaturas, em que não havia lugar para a ciência linguística" (RODRIGUES, 2005, p.13). O agravamento dessa questão, para Rodrigues, dá-se ainda por ser este o modelo de faculdade tomado pelo Ministério da Educação para pautar as demais faculdades de Filosofia, Ciências e Letras do Brasil.

Em sua tese, Martins (2012), após um levantamento sobre a institucionalização da Linguística no Brasil e suas respectivas condiçóes de produção, aponta para o fato de que a Linguística, no Brasil, apresenta 
diferentes orientaçóes e modos de entrada, para a autora, "diferentes são os percursos de institucionalizaçáo das pesquisas linguísticas no Brasil (no interior de cada universidade) até a década de 1960, quando um decreto do Ministério da Educação a torna uma disciplina obrigatória nos Cursos de Letras". Para a pesquisadora, esses caminhos podem ser observados por meio do percurso de alguns professores, já que, inicialmente, as pesquisas linguísticas interessaram a poucos. De acordo com a autora:

[...] o início da Linguística no Brasil está fortemente ligado, portanto, à postura político-teórica do sujeito-professor (aliada, claro, às condiçôes institucionais)", pois, é a formaçáo destes profissionais que determinou as linhas teóricas seguidas na Linguística brasileira. Inicialmente foram os grandes filólogos que ocuparam as principais cátedras universitárias do país e fundaram os primeiros centros de pesquisa dedicados a temas dessa natureza (MARTINS, 2012, p. 62).

A pesquisadora afirma ainda que "o processo de institucionalização da Linguística só veio a consolidar-se ampla e definitivamente nos anos 60, por meio de uma resolução do Conselho Federal de Educação (CFE)" (MARTINS, 2012, p. 61). No ano de 1961, o CFE determinava, para o ano seguinte, a implantação da disciplina de Linguística em todas as Faculdades de Filosofia que tivessem curso de Letras.

Castilho (1963, p. 27) aponta para o fato de que o alinhamento da Linguística entre as disciplinas básicas é "digna de aplauso", mesmo considerando as ponderaçôes de Rodrigues que, em Brasília, no ano de 1963, argumentava náo haver um número suficiente de linguistas aptos a ministrarem a disciplina. De acordo com Rodrigues (2005), na época em que a resolução do CFE a respeito da obrigatoriedade da Linguística foi implementada, havia apenas três professores formados na área: ele próprio Aryon Rodrigues, Mattoso Câmara e Francisco Gomes de Matos.

\section{Aryon Rodrigues e a Linguística no Brasil}

Conforme vimos anteriormente, no Brasil, a instituição da Linguística como componente curricular dos cursos de Letras ocorreu de forma tardia, uma vez que a obrigatoriedade do ensino dessa disciplina se deu apenas em 1962, com o Parecer no 283/62 do Conselho Federal de Educação. Conforme Luz (2010, p. 98), nesse período, de modo institucional, "surgiu a linguística moderna no Brasil, ligada às novas condiçôes dos estudos sobre a linguagem, propiciadas pela implantação da disciplina de linguística nos 
cursos superiores de Letras". E foi nesse mesmo ano que o professor Aryon Rodrigues chegou à Universidade de Brasília (UNB) - a convite do ministro da educação Darcy Ribeiro - para chefiar o departamento de Linguística, organizando um mestrado na área.

Entretanto, conforme Altman (2004), o próprio Aryon ficou surpreso com essa resolução, temendo as consequências que ela traria em razão do número ínfimo de profissionais habilitados a trabalhar com a recente disciplina nas universidades. Segundo a autora, Aryon Rodrigues considerava um começo inadequado atrelar o estudo da Linguística a essa obrigatoriedade, "[...] porque a precipitaçáo da medida favorecia a improvisação e comprometeria o desenvolvimento dos estudos na então nova disciplina” (ALTMAN, 2004, p. 114).

Mesmo diante desse cenário, o professor aceitou o desafio e permaneceu à frente do departamento. Rodrigues, logo que chegou em Brasília (1963), criou um curso intensivo que promoveu a preparação dos professores universitários que ministrariam a disciplina de Linguística. Ainda em 1963, implantou em Brasília o primeiro departamento autônomo de Linguística e o primeiro programa de Pós-Graduação (em nível de mestrado) voltado para pesquisadores em Linguística (curso que funcionou somente até o ano de 1965, devido a intervençóes e demissōes ocorridas após a revolução de 1964).

Aryon atuou também, na UNB, em conjunto com o Departamento de Antropologia, na criação do Centro de Culturas e Línguas Indígenas, adentrando na área que o tornaria reconhecido internacionalmente. Entendemos, porém, que - ainda que seu nome seja constantemente associado ao estudo das línguas indígenas - Aryon Rodrigues exerce um papel importantíssimo na fundação da Linguística brasileira. Concordamos com D’Angelis (2006, p. 14), quando afirma que “[...] em nosso país, a história da linguística não pode ser contada sem referência a, pelo menos, dois nomes (se outros forem esquecidos): Joaquim Mattoso Câmara Jr. e Aryon Dall'Igna Rodrigues".

Embora a Linguística seja incluída nos currículos mínimos no ano de 1962, é, a partir de 1968, de acordo com Altmann (1998), que se concentra um conjunto de fatores de ordem intelectual e social que permite, em vários pontos do país, a solidificação institucional de uma "Linguística brasileira" e, consequentemente, de um jovem grupo de pesquisadores que começam, a partir de então, a se reconhecerem "linguistas". Com isso, apesar de 1968 não ser, de fato, o ano da institucionalização obrigatória da disciplina, este é o ano que marcaria o reconhecimento dos pesquisadores na área. 
A disciplina Linguística dessa época, no Brasil, também apresenta uma forte ligação com a Antropologia. No Museu Nacional (RJ), em 1968, foi criado um Curso de Pós-Graduação em Linguística, cujos professores eram, na sua maioria, antropólogos, com exceção de Rodrigues. Dois anos mais tarde, o Curso do Museu Nacional foi agregado à Faculdade de Filosofia. Em decorrência dessa mudança institucional, Rodrigues e parte de sua equipe transferiram-se para a Universidade Estadual de Campinas, no ano de 1973, onde continuaram seus trabalhos na área de Linguística.

Em relação à institucionalização da disciplina de Linguística no país, Guimarães afirma que:

[...] a década de 1960 trará consigo novos contornos institucionais. Começa com a obrigatoriedade de inclusão da linguística nos currículos de letras e termina com a criação do sistema nacional de pós-graduação e a criação dos primeiros programas de pós-graduação em Linguística do Brasil (GUIMARĀES, 2004, p. 42).

A respeito desses contornos institucionais e das mudanças ocorridas nas grades curriculares dos cursos de Letras na década de 1960, podemos observar, por meio de texto publicado na revista $A L F A$, pelo professor Castilho (1963), que se estava buscando soluçóes para a implementação efetiva da disciplina de Linguística no país. Cabe ressaltar que, para nós, a Linguística praticada nas universidades, naquele momento, está ligada também ao estruturalismo, divulgado por Mattoso Câmara (Saussure) e Aryon Rodrigues (Sapir e Bloomfield).

Para Castilho (1963), a inclusão da disciplina de Linguística entre as disciplinas básicas é algo notoriamente positivo. Entretanto, o autor não deixa de expor em seu texto as ponderaçóes do professor Aryon Rodrigues, o qual argumenta náo haver, no Brasil, na época, 73 linguistas para igual número de Faculdades de Filosofia, o que causaria um problema para o desenvolvimento da disciplina, já que as faculdades, vendo-se obrigadas a ofertá-la, contratariam profissionais mesmo sem preparo adequado.

Como sugestôes para que não ocorressem "disparates" no ensino da Linguística, Rodrigues propôs que essa disciplina fosse oferecida em séries mais avançadas, para que pudesse ser "treinada" uma equipe de linguistas por meio de um curso intensivo na Universidade de Brasília (UNB). O linguista também apoiou a contratação de professores estrangeiros (o que só seria possível em instituiçóes oficiais). 
É importante ressaltar que, nos anos 1950 e 1960, as Faculdades de Filosofia e Letras tinham por objetivo único a formação de professores, sem incentivo à pesquisa acadêmica. Isso significa que a instituição acadêmica, tal qual nos foi apresentada por muitos anos, principalmente nos Cursos de Licenciatura, tinha por finalidade somente ensinar, "repassar" conceitos e teorias e, como foi mencionado, não visava formar pesquisadores, o que já não é mais o caso atualmente, uma vez que, desde cedo, o estudante pode se interessar pela formação em pesquisa através de programas de iniciação científica.

Somente no final da década de 1970, um maior grupo de alunos formados em cursos de Linguística começou a interessar-se também por pesquisas. Para Altmann (1998), ao invés de lugar de pesquisa, as universidades eram consideradas, até então, apenas lugares oficiais de ensino/aprendizagem que visavam formar professores de línguas.

Nos anos 1970, ocorre a regulamentação dos Cursos de Pós-Graduação no país, o que se constitui em um desafio para a Linguística, devido tanto à falta de recursos materiais quanto à falta de recursos humanos. Considerando esse contexto, pode-se afirmar que é a partir dos anos 70 que a Linguística passou a constituir um domínio específico e autônomo de investigação. Em relação aos movimentos da política de Pós-Graduação brasileira, Guimarães afirma que:

[...]acabaram por colocar em convívio permanente no Brasil pesquisadores formados em centros diversos, principalmente dos Estados Unidos e da Europa. Assim o debate linguístico no Brasil é marcado por essa capacidade de movimentar formaçóes que, muitas vezes, não se conversam tão diretamente como no Brasil (GUIMARÃES, 2004, p.39).

Portanto, a Linguística brasileira é permeada por diferentes filiaçóes teóricas, tanto as trazidas pelos primeiros professores europeus, que se deslocaram para o Brasil a fim de ministrar disciplinas nos Cursos de Letras e de Linguística, quanto as trazidas pelos linguistas brasileiros ao complementarem seus estudos no exterior. Isso converge na atual heterogeneidade das linhas de trabalho presentes nos Cursos de PósGraduação em Letras e Linguística do país. 


\section{O efeito metafórico no processo de designaçáo}

Nas análises que se seguem, buscamos compreender como a memória entra em funcionamento no processo de designação de Aryon Rodrigues, entendendo que é por meio do deslizamento de sentidos que a memória se atualiza e os dizeres se tornam outros. Para constituiçáo de nosso corpus, optamos por uma prática muito comum na atualidade, a pesquisa em sites de busca. Assim, inserimos o nome do linguista no Google e fomos automaticamente levadas aos enunciados que compóem nosso corpus. A fim de estabelecer a delimitação de nossos recortes, procuramos selecionar apenas os ditos em torno da morte do linguista, em diversos espaços de significação, para que pudéssemos nos debruçar no estudo do processo de designação e no efeito metafórico que o constitui.

Entendemos como necessário, aqui, antes de iniciarmos nossas análises, demarcar o lugar de onde falamos a respeito da metáfora. Em nossa percepção, ancorada no aporte teórico da Análise de Discurso francesa, a metáfora extrapola a simples oposição ao sentido literal. Compreendemos a metáfora como constitutiva dos sentidos, uma vez que, como nos aponta Orlandi (1996, p. 21), "o sentido é sempre uma palavra, uma proposição por outra: os sentidos só existem nas relaçóes de metáfora dos quais certa formação discursiva vem a ser o lugar mais ou menos provisório."

Conforme apontamos anteriormente, Aryon Rodrigues é dono de uma produção acadêmica significativa no que concerne às línguas indígenas. Em relação a essa produção, tomamos uma das metáforas que mais nos chamou atenção com relação ao anúncio da morte de Aryon Rodrigues. No dia 04 de maio de 2014, no Blog da Amazônia, foi publicada a seguinte manchete: 


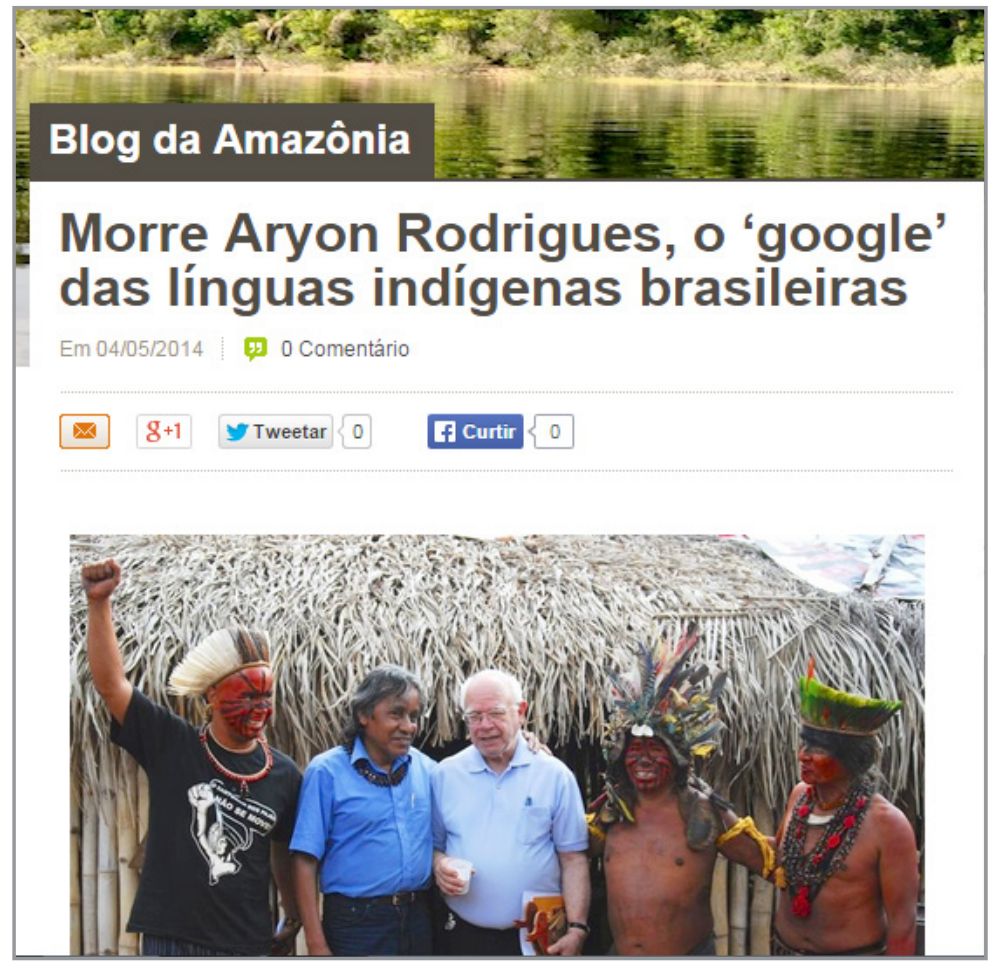

Recorte Discursivo 1: Google das línguas indígenas ${ }^{1}$

Compreendemos que, nesse processo de designação, são mobilizados sentidos que provocam um efeito de predicaçáo em que a um nome são associados sentidos possíveis. Assim, o grande pesquisador Aryon Rodrigues, que, até dezembro de 2013, publicou mais de 150 artigos sobre diferentes línguas indígenas, é o grande conhecedor, capaz de responder qualquer pergunta sobre o tema, assim como a ferramenta de busca mais conhecida na atualidade, o Google. Esses deslizamentos de sentido que se dão no dizer só são possíveis por meio do efeito metafórico.

Nas palavras de Pêcheux (2009, p. 96), o efeito metafórico é o "o fenômeno semântico produzido por uma substituiçáo contextual" que provoca um "deslizamento de sentidos". Esse efeito metafórico que é

1 Fonte: http://noticias.terra.com.br/brasil/blogdaamazonia/blog/2014/05/04/morre-aryonrodrigues-o-google-das-linguas-indigenas-brasileiras/. Acesso em 13 maio 2015. 
constitutivo da produção de sentidos se torna possível por mobilizar dizeres outros que se encontram na base do já-dito, na memória do dizer. Conforme Scherer e Taschetto (2005), esses implícitos que residem na memória discursiva se constituem "ausentes por sua presença, disponíveis em um registro oculto, encontráveis na 'regularização' sob a forma de remissóes, de retomadas e de efeitos de paráfrase" (SCHERER; TASCHETTO, 2005, p. 121). Compreendemos, então, que, na formulação Google das línguas indígenas ( $\mathrm{RD} 1$ ), entra em funcionamento o efeito da memória, que retoma e atualiza discursos para que se produzam novos sentidos, nos quais irrompe o lugar discursivo ocupado por Aryon Rodrigues, que passa a ser enunciado, materializado no intradiscurso.

Para Scherer (2008, p. 133), "o lugar não pode ser entendido como algo pleno, com bordas delimitadas tâo somente pelas ditas fronteiras e domínios, mas como um espaço movente de disjunçóes, deslocamentos e retomadas, de conflitos de regularização". Esse lugar, portanto, não se constitui como espaço físico estático, mas se relaciona com a representação como processo imaginário atravessado por processos de identificação. Nesse sentido, concordamos com Dias (2009, p. 3) quando afirma que desses processos de identificação "são constitutivas as condiçóes de produção, o imaginário do sujeito-autor e do sujeito-leitor".

O Google das línguas indigenas é, portanto, uma formulação baseada no imaginário que associa Aryon ao conhecimento sobre essas línguas, que, em um deslizamento de sentidos, nos remete ao site de busca capaz de localizar qualquer informação, uma espécie de oráculo desse saber. Esse deslocamento só produz sentidos em razão de suas relaçóes intrínsecas com as condiçôes de produção - que envolvem, também, o modo de veicular a informação. É assim que, em um blog lido por usuários da internet que são, ao mesmo tempo, interessados pela temática indigenista, Aryon se torna o Google.

O lugar de Aryon como dono do saber sobre as línguas indígenas é reforçado quando analisamos algumas outras formulaçóes acerca de sua morte, também veiculadas na mídia eletrônica, conforme observado nos Recortes Discursivos abaixo: 


\section{Morre aos 88 anos, professor da UnB referência em línguas indígenas}

\section{Aryon Dall'Igna Rodrigues fundou o Laboratório de Linguas Indigenas do Instituto de}

Letras (Laic)

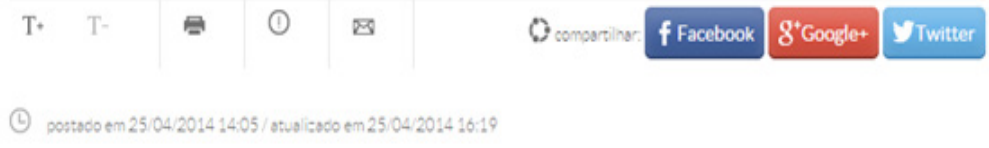

Recorte Discursivo 2 - Referência em Línguas Indígenas ${ }^{2}$

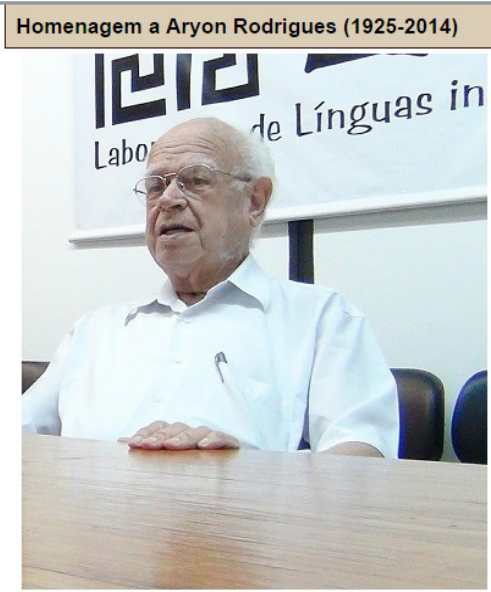

Faleceu, no último dia 24 de abril, o grande linguista brasileiro, Aryon Dall'Igna Rodrigues. Aryon era o maior especialista em linguas indigenas do Brasil, reconhecido internacionalmente.

Recorte Discursivo 3 - O maior especialista em línguas indígenas do Brasil ${ }^{3}$

2 Fonte: http://www.correiobraziliense.com.br/app/noticia/cidades/2014/04/25/interna cidadesdf, 424722/morre-aos-88-anos-professor-da-unb-referencia-em-linguas-indigenas. shtml. Acesso em: 02 maio 2015.

${ }^{3}$ Fonte: http://www.portal.abant.org.br/index.php/in-memoriam. Acesso em: 05 maio 2015. 


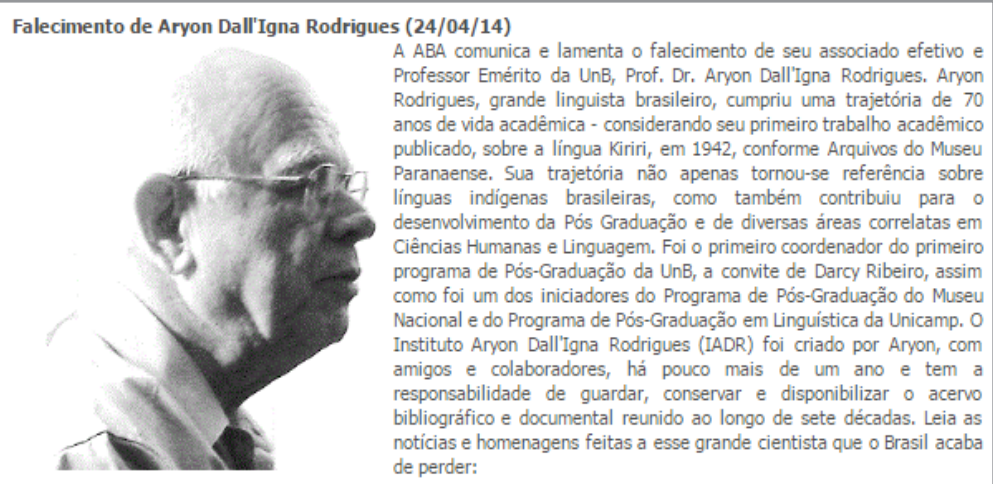

http://www.kamuri.org.br/kamuri/;

http://www.portalkaingang.org/index_home.html;

http://www.correiobraziliense.com.br/app/noticia/ciencia-e-saude/2012/12/09/interna_ciencia_saude,338255/aryon-

rodrigues-existem-mais-de-200-linguas-e-so-se-ensina-portugues.shtml.

Recorte Discursivo 4 - Grande Linguista Brasileiro

Compreendemos que, em torno das formulaçōes referência em línguas indigenas (RD 2), maior especialista em línguas indigenas do Brasil (RD3) e grande linguista brasileiro (RD 4 e RD 5), se instauram redes parafrásticas que, por meio da repetição, produzem o efeito de enaltecer a figura do pesquisador. Com relação aos processos parafrásticos, Orlandi (2012) nos diz que:

[...] são aqueles pelos quais em todo dizer há sempre algo que se mantém, isto é, o dizível, a memória. A paráfrase representa assim o retorno aos mesmos espaços do dizer. Produzem-se diferentes formulaçóes do mesmo dizer sedimentado. A paráfrase está do lado da estabilização (ORLANDI, 2012, p. 36).

Assim, por meio dos qualificadores grande (RDs 4 e 5) e maior ( $R D$ 3) encontramos algo que se mantém, há um retorno à memória de Aryon Rodrigues, a memória presente no interdiscurso e que produz efeitos no fio do dizer. Aryon é grande porque sua contribuiçáo para o estudo das línguas indígenas é grande, e é maior porque sua produção é a maior entre os demais linguistas da área, o que o torna referência brasileira (RD 2). Conforme D’Angelis (2014, p. 510, grifos da autora), "Aryon é autor da mais importante obra de divulgação sobre línguas indígenas brasileiras, o famoso 'livrinho verde de Aryon': Línguas brasileiras: para o conhecimento das 
línguas indígenas”. Compreendemos que há redes de significação em torno dessas formulaçóes que produzem sentido por fazerem funcionar a memória, que, mesmo não sendo do nível da evidência, está no cerne da significação. Afinal, "é pela memória (interdiscurso) e seus funcionamentos, que os discursos se entrelaçam, convocando e fazendo trabalhar discursos inscritos em diferentes domínios, possibilitando que os não-ditos, os a-dizer e o dizer encaminhem e legitimem sentidos outros" (VENTURINI, 2012, p. 77).

Além do estatuto de importância atribuído a Aryon Rodrigues, o uso do determinante maior, que funciona como adjunto adnominal do substantivo especialistas, pode remeter a sentidos que vão além daqueles comumente relacionados ao adjetivo em questáo. Conforme o dicionário Houaiss, a essa palavra também estão atrelados sentidos que retomam a questão de origem - uma vez que, na acepção do verbete nesse dicionário, encontramos uma derivaçáo imprópria em que a palavra maior é definida como ancestrais, antepassados ou ascendência. Nesse mover dos sentidos, compreendemos que é retomado o papel fundador de Aryon em relação à Linguística, em especial ao estudo das línguas indígenas.

$\mathrm{O}$ adjetivo grande, que funciona como determinante do núcleo do sujeito linguista, também desliza para produzir um efeito de grandiosidade e enaltecimento, ao desviar-se de seu sentido literal, deslocando-se de seu significado base. Assim, deixa de ter relação com o tamanho físico, denotando variação de grau, e passa a significar em relação ao lugar representado por Aryon Rodrigues no campo social, intelectual e, inclusive, político - pela visibilidade que conferiu às questóes da cultura indígena. Entendemos, portanto, que ressoam nessas formulaçóes aspectos relacionados à produção intelectual do pesquisador e seu papel na instituição da ciência linguística. Apoiamos nossa análise nas ideias de Serrani (1993), quando afirma que:

Há paráfrase quando podemos estabelecer entre as unidades envolvidas uma ressonância - interdiscursiva - de significação, que tende a construir a realidade (imaginária) de um sentido. Ressonância porque para que haja paráfrase a significação é produzida por meio de um efeito de vibração semântica mútua (SERRANI, 1993, p. 47).

Essas redes parafrásticas que irrompem no gesto de designar Aryon Rodrigues produzem efeitos de sentido que constituem sujeitos distintos no processo de designação, afetados pelo simbólico e pelo político. Para Guimarães (2005), a designação é a significação de um nome, mas não como algo abstrato. Nas palavras do autor, "seria a significação enquanto algo 
próprio das relaçôes da linguagem, mas enquanto uma relação linguística (simbólica) remetida ao real, exposta ao real, ou seja, enquanto uma relação tomada na história" (GUIMARÃES, 2005, p. 9).

Em nosso entendimento, no discurso sobre Aryon Rodrigues - nas notas dedicadas ao seu falecimento, por meio do processo de designação - há um efeito de testemunho, comum ao discurso do epitáfio, numa tentativa de, através das palavras, estabelecer um lugar discursivo do falecido na memória social.

\section{Consideraçóes finais}

Aryon Rodrigues se constitui como um ícone da produção acadêmica, a quem tanto a Antropologia quanto a Linguística devem muito. Por meio deste estudo, foi possível compreender a importância atribuída a esse pesquisador e as relaçóes de sentido estabelecidas no ato de designar Aryon Rodrigues em razão de seu desaparecimento.

Compreendemos que essa designação se instaura por meio do efeito metafórico que possibilita o deslizamento de sentidos em torno da imagem do linguista. Nesse sentido, por mais que na formulação esses dizeres se organizem em torno do diferente, há algo que se mantém no processo de adjetivaçáo decorrente do designar como efeito de predicação.

Consideramos interessante o fato de que o $\mathrm{RD} 4$, extraído da nota de falecimento divulgada pela Associação Brasileira de Antropologia, seja justamente a formulação em que não houve menção ao trabalho do autor como indigenista. Em outras palavras, no discurso do espaço em que Aryon mais atuou na pesquisa das línguas indígenas, ocorre um efeito de generalização que, em nosso ver, não remete ao apagamento do linguista como pesquisador da antropologia, mas como uma demarcação de um espaço mesmo/outro de significação em que o Aryon Rodrigues da antropologia é representado também na Ciência Linguística.

Assim, entendemos que pensar Aryon Rodrigues - seja como Google das linguas indígenas, como referência em linguas indígenas, como o maior especialista em linguas indigenas do Brasil, ou como o grande linguista brasileiro - é reconhecer sua atuação como pesquisador que muito contribuiu para a constituição da Linguística no país e possibilitar a assunçáo de um lugar na memória dessa Ciência e de todos aqueles que por ela se interessam. 


\section{Referências}

ALTMAN, Cristhina. A pesquisa Linguística no Brasil (1968 - 1988). São Paulo: Humanitás; FFLCH; USP, 2004.

CASTILHO, Ataliba. A reforma dos Cursos de Letras. Revista Alfa, v. 1, p. 05-38, março de 1963.

D’ANGELIS, Wilmar da R.. Aryon das línguas Rodrigues. Estudos da Língua(gem), vol. 4, n. 2. Vitória da Conquista: UESB, p. 13-19, 2006.

Aryon Rodrigues: 70 anos dedicados à Linguística e às Línguas Indígenas. DELTA, v. 30. São Paulo. 2014. Disponível em: http://www. scielo.br/scielo.php?pid=S0102-44502014000300503\&script=sci_arttext. Acesso em: 16 maio 2015.

DIAS, Juciele P. Um lugar de representação do saber. In: Seminário de Estudos em Análise do Discurso, IV. Anais. UFRGS: Porto Alegre, 2009. Disponível em: http://anaisdosead.com.br/4SEAD/POSTERES/ JucielePereiraDias.pdf. Acesso em: 25 maio 2015.

FIORIN, José. L. A criação dos cursos de Letras no Brasil e as primeiras orientaçôes de pesquisa Linguística universitária. Revista Língua e Letras, p. 11-25, v 7, n. 2. $1^{\circ}$ sem 2006. Disponível em http://www.unioeste.br/ saber. Acesso em: 25 maio 2015.

GUIMARÁES, Eduardo. Semântica do Acontecimento. Campinas: Pontes, 2005.

LUZ, Mary Neiva Surdi da. Linguística e ensino: discurso de entremeio na formação de professores de Língua Portuguesa. 2010. 284 p. Tese (Doutorado em Letras) - Universidade Federal de Santa Maria, Santa Maria (RS), 2010.

MARTINS, Taís S. Efeitos de Sentido na Disciplinarizaçáo de uma Teoria. 2012. 176 p. Tese (Doutorado em Letras) - Universidade Federal de Santa Maria, Santa Maria (RS), 2012.

ORLANDI, Eni P. Língua e conhecimento linguístico: para uma História das Ideias no Brasil. São Paulo: Cortez, 2002.

RODRIGUES, Aryon D. A obra científica de Mattoso Câmara Jr. Revista de Estudos da Linguagem, Vitória da Conquista, BA, v. 2, p. 11-28, 2005. 
SCHERER, Amanda E. Dos domínios e das fronteiras: o lugar fora do lugar em outro e mesmo lugar. In: SARGENTINI, Vanice; GREGOLIN, Maria do Rosário (Org.). Análise do discurso: heranças, métodos e objetos. São Carlos: Claraluz, 2008.

PÊCHEUX, Michel. Semântica e discurso: uma crítica à afirmação do óbvio. 4. ed. Campinas (SP): Unicamp, 2009.

VENTURINI, Maria. C. Gramática e ensino: uma discussão na perspectiva do texto e do discurso. Matraga, Rio de janeiro, v. 19, n. 30, jan./jun. 2012. 